\title{
Short- and long-term factors in tolerance to morphine-induced antinociception: Single or multiple mechanisms?
}

\author{
COLLEEN R. MCLAUGHLIN \\ Dartmouth College, Hanover, New Hampshire \\ and Medical College of Virginia/Virginia Commonwealth University, Richmond, Virginia \\ WILLIAM L. DEWEY \\ Medical College of Virginia/Virginia Commonwealth University, Richmond, Virginia \\ and \\ MICHAEL S. FANSELOW \\ University of California, Los Angeles, California
}

\begin{abstract}
Data from several laboratories indicate that Pavlovian conditioning plays an important role in the formation of tolerance to the antinociceptive effect of morphine. The two prominent theories aimed at explaining these properties are those that suggest that tolerance is the result of conditioned compensatory processes (Eikelboom \& Stewart, 1982; MacRae, Scoles, \& Siegel, 1987; Siegel, 1975) and those based on Wagner's $(1976,1978)$ priming model of habituation (Baker \& Tiffany, 1985; Paletta \& Wagner, 1986). Using the procedure previously described by Tiffany and Maude-Griffin (1988) and the method of continuous infusion (Lightman \& Young, 1987; Schaefer \& Michael, 1986), we tested two predictions generated by the priming model of tolerance: that short and long retention of tolerance should develop at the expense of each other and that only tolerance resulting from long interdose interval (IDI) acquisition parameters should display long-term retention. All animals preexposed to morphine displayed shorter pawlick latencies than did the saline-treated controls in response to morphine during testing. This indicated tolerance, regardless of acquisition IDI or the length of time between last drug preexposure and test. Contrary to the prediction of the Baker and Tiffany model (1985), these results demonstrate that tolerance resulting from both short and long IDI acquisition parameters can be long-lasting.
\end{abstract}

Conditioned drug effects were first cited by Pavlov in 1924 (see Pavlov, 1960). Since this initial report, others have suggested that psychological processes may modulate an animal's response to certain drug actions (Adams, Yeh, Woods, \& Mitchell, 1969; Baker \& Tiffany, 1985; Cohen, Keats, Krivoy, \& Ungar, 1965; Eikelboom \& Stewart, 1982; MacRae, Scoles, \& Siegel, 1987; Siegel, 1975; Smith, Karmin, \& Gavitt, 1966; Tiffany \& Baker, 1981). Most recently, several researchers have postulated that tolerance to the antinociceptive properties of morphine may follow the laws of Pavlovian conditioning

Experiment 1 was submitted in partial fulfiliment of the requirements for the PhD degree by Colleen R. McLaughlin. We wish to thank the other members of the committee; Catherine P. Cramer, Howard C. Hughes, and Dennis W. Coombs. We would also like to thank Aron $H$. Lichtman for his numerous comments and insights, Joe Pretlow for his technical assistance, and the Penick Corporation for the morphine sulfate. Portions of this research were supported by NIDA Grants DA01647 and DA-07027, and by the Commonwealth of Virginia Center on Drug Abuse Research. Correspondence should be addressed to Colleen R. McLaughlin, Pharmacology/Toxicology, Medical College of Virginia/Virginia Commonwealth University, MCV Station Box 613, Richmond, VA 23298.
(Baker \& Tiffany, 1985; Eikelboom \& Stewart, 1982; MacRae et al., 1987; Paletta \& Wagner, 1986; Siegel, 1975). These conditioning theories can be divided into two types: those based on conditioned compensatory responses, and those relying on the priming of memorial processes. The conditioned compensatory response models suggest that tolerance is associative and longlasting (Eikelboom \& Stewart, 1982; MacRae et al., 1987; Siegel, 1975). Priming models, on the other hand, predict two types of tolerance: long- and short-term, which are associative and nonassociative, respectively (Baker \& Tiffany, 1985; Paletta \& Wagner, 1986).

The priming models of tolerance suggest that morphine tolerance and habituation occur as a function of similar memorial processes (Baker \& Tiffany, 1985; Paletta \& Wagner, 1986). According to Wagner's priming theory $(1976,1978)$, stimuli are processed to the extent that they are surprising, and the magnitude of the unconditioned response (UR) is then determined by the amount of processing that has occurred. Thus presentation of an event that is already primed in short-term memory (STM) will result in less processing of that event as well as a diminished response to presentation of the event. Habit- 
uation is assumed to reflect this diminished response. Events can be primed in STM by either self-generated priming or associatively generated priming. In selfgenerated priming, the stimulus is already in STM due to an earlier presentation of the same stimulus. In associatively generated priming, on the other hand, the stimulus is primed in STM after the presentation of a cue previously paired with the stimulus. Therefore, presentation of morphine without a cue, or without priming, would be a surprising event and would result in increased processing and a larger UR. Conversely, presentation of morphine with a cue or after a recent exposure would not be a surprising event and would result in decreased processing and a smaller UR.

If tolerance to morphine occurs as a function of priming, it follows that two types of tolerance are subserved by the two different types of priming. The first type of tolerance is associative, in that after several pairings of the drug with a cue, the cue will cause retrieval of the stimulus properties of the drug into STM. Therefore, when the cue is presented in the future it will cause recall of-or it will prime-the stimulus properties of the drug, and the UR to a subsequently presented drug will be diminished. The other type of tolerance, nonassociative tolerance, is not a direct result of associative manipulations (Kesner \& Cook, 1983) and results from selfgenerated priming. Therefore, if a drug-induced stimulus is presented while the stimulation from an earlier presentation is still primed in STM, it will be less surprising and will result in less processing. Consequently, the UR will be diminished.

The distinction between associative and nonassociative tolerance is similar to the distinction between short- and long-term habituation made by Davis (1970). In shortterm habituation, closely spaced stimuli that are presented before the preceding stimulus has left STM provide a continuous representation of the stimulus in STM. The continued representation of the stimulus in STM, selfgenerated priming, results in a rapid decrease in responding. Long-term habituation, on the other hand, occurs when the stimuli are spaced at longer intervals. It is hypothesized that the longer intertrial interval allows for the storage of the stimulus into long-term memory (LTM) along with the associative cues that were paired with it. Long-term habituation does not occur as rapidly as shortterm habituation, but it has a longer retention, because short-term habituation continues only as long as the stimulus remains in STM. As would be expected, self-generated priming is most effective when the interdose interval (IDI) is short and the dose high, which would result in the sustained presence of the drug. This increase in nonassociative tolerance as a function of dose occurs because higher doses result in longer maintenance of the drug in STM and a concomitant increase in self-generated priming. The continued presence of the drug, however, would interfere with long-term tolerance because it would interfere with the rehearsal and storage into LTM of the cues associated with the drug. Therefore, future presentations of the cue do not prime the drug or result in diminished responding.

Tiffany and Maude-Griffin (1988) have recently tested one of the predictions made by Baker and Tiffany (1985): that the tolerance resulting from long IDIs (long-term tolerance) is sensitive to associational cues, whereas the tolerance resulting from short IDIs (short-term tolerance) is relatively insensitive to associational cues. Their results suggest that long-term tolerance appears to be sensitive to contextual cues, whereas short-term tolerance is not. It is possible, however, that both short- and long-term tolerance are associative and long-lasting, but that in each paradigm different contextual cues are relevant. For example, Walter and Riccio (1983) have suggested that the initial stimulation of morphine may act as a cue for itself and that at high doses these morphine cues may overshadow other contextual cues. Furthermore, the initial stimulation associated with morphine administration (e.g., handling, needle insertion, the initial stimulation from the drug) may be a more relevant stimulus for morphine's later antinociceptive effects than the somewhat arbitrarily assigned nominal conditioned stimuli (CSs) (e.g., odors, lighting) and, thus, results in better conditioning (Garcia \& Koelling, 1966). Consequently, there are two potential explanations of tolerance with short IDIs: short-term habituation and overshadowing.

Dafters and Bach (1985) have tested between these two accounts of short-term tolerance by examining the effect of a 14-day "rest" period on tolerance. If tolerance is the result of short-term habituation, then some decay of habituation would be expected after the 14-day interval. If, however, tolerance is the result of Pavlovian conditioning, no change in the response would be expected in the absence of an extinction manipulation. Their results indicated no evidence of recovery of the antinociceptive properties of morphine after 14 days of rest in either the distinctive or the nondistinctive environment condition. These data suggest that tolerance is not subserved by two types of habituation, but rather by differing classes of stimuli, as Water and Riccio have suggested (1983). However, more recent work from Dafters's lab, which indicates that the rapidity of acquisition, contextual specificity, and length of retention of tolerance are inversely correlated with the acquisition dose and IDI, supports the priming model (Dafters \& Odber, 1989; Dafters, Odber, \& Miller, 1988).

Another method that could be employed to test between the two hypotheses would be to manipulate the IDI and dose. The habituation theory of tolerance predicts that IDI and dose determine the difference in retention time between short- and long-term tolerance. Short-term tolerance is formed, at the expense of long-term tolerance, with high doses and low IDI, because the sustained presence of morphine required for self-generated priming prevents the rehearsal necessary for the formation of retrievalgenerated priming and long-term tolerance. Conversely, long-term tolerance is formed at the expense of short-term tolerance, with lower doses and longer IDIs, parameters 
that prevent the sustained presence of the drug needed for self-generated priming and short-term tolerance. Therefore, we tested two predictions generated by Baker and Tiffany's (1985) priming model of conditioned morphine tolerance: that short- and long-term tolerance ${ }^{1}$ are subserved by different mechanisms and should develop at the expense of one another, and that only long-term tolerance should have a long retention. This was accomplished by keeping dose constant and manipulating the IDI. Following either massed or spaced acquisition conditions, we assessed tolerance following short or long retention intervals. In Experiment 1, we induced tolerance with the parameters established by Tiffany and Maude-Griffin (1988). In Experiment 2, we used the method of continuous infusion (Lightman \& Young, 1987; Schaefer \& Michael, 1986). To assess tolerance to morphine's analgesic efficacy, we used the hotplate test of nociception (Woolfe \& MacDonald, 1944). The animals were tested with a single probe dose of morphine that had previously been shown to discriminate between morphine-tolerant and morphine-naive animals (McLaughlin, Lichtman, Fanselow, \& Cramer, 1989). This technique allowed us to make qualitative but not quantitative assessments of tolerance with a minimum number of animals. If Baker and Tiffany's (1985) prediction is correct, animals in the massed acquisition condition/long retention interval would be expected to show less tolerance than the animals in the massed acquisition condition/short retention interval.

\section{EXPERIMENT 1}

\section{Method}

Subjects. The subjects in the first experiment were male LongEvans-derived hooded rats, initially weighing approximately 400-500 g, descended from animals obtained from Blue Spruce Farms (Altamont, NY). The animals were housed individually, with food and tap water continuously available, on a 14:10-h light:dark cycle. The experiments were conducted during the light phase. All animals were preexposed to handling for several days prior to the start of the experiment. A total of 75 animals provided an $N$ of 9-10/cell.

Apparatus. The apparatus employed for nociceptive testing in both experiments was an IITC, Inc., MOD 35-D hotplate $\left(51.5^{\circ} \pm 0.5^{\circ} \mathrm{C}\right)$. Plexiglas walls $(45 \mathrm{~cm}$ high) surrounded the hotplate to prevent escape.

Procedure. The animals were subdivided into either morphine ( $30 \mathrm{mg} / \mathrm{kg}$, i.p.) or isotonic saline drug preexposure groups. These two groups were then reassigned to either the massed or the spaced acquisition condition, thereby resulting in a $2 \times 2$ factorial design with respect to drug group and acquisition condition. Following the procedure described by Tiffany and Maude-Griffin (1988), animals in the massed acquisition condition were administered the drug at 24-h intervals, whereas animals in the spaced acquisition condition were administered the drug at 96-h intervals. The animals in both acquisition conditions, massed and spaced, received a total of seven drug exposures. Immediately following each drug exposure, the animals were briefly placed on the unheated hotplate surface, because previous data indicated that experience with the nociceptive test facilitates the expression of tolerance ${ }^{2}$ (Adams et al., 1969; Advokat, 1981; Bardo \& Hughes, 1979; Kayan, Woods, \& Mitchell, 1969; Sherman, Proctor, \& Strub, 1982). After the last drug preexposure, all of the groups were again subdivided into either the short ( $24 \mathrm{~h}$ after final drug exposure) or long retention ( $96 \mathrm{~h}$ after final drug exposure) interval, thereby resulting in a $2 \times 2 \times 2$ factorial design with respect to drug group, acquisition condition. and retention interval.

Earlier data from our laboratory indicate that subtle changes in laboratory conditions may have an impact on the performance of tolerance (McLaughlin et al., 1989). Therefore, acquisition for the massed acquisition condition/short retention interval was started $72 \mathrm{~h}$ after that for the massed acquisition condition/long retention interval, thus allowing all behavioral testing to occur on the same day under similar laboratory conditions.

On the day of testing, all animals were administered a probe dose of morphine previously found to discriminate between morphinetolerant and morphine-naive animals (McLaughlin et al., 1989) (10 mg/kg, i.p.), and they were then returned to their home cages. Thirty minutes later, they were removed from their cages and gently placed on the hotplate surface $\left(51.5^{\circ} \pm 0.5^{\circ} \mathrm{C}\right)$. Latency to lick a hindpaw, to the nearest second, was the dependent measure. Animals not licking a hindpaw before the 60 -sec cutoff were given the maximum score. A total of 75 animals provided a final $N$ of $9-10 /$ cell.

\section{Results and Discussion}

As expected, morphine-preexposed animals in the spaced acquisition condition, regardless of retention interval (short or long), displayed shorter pawlick latencies than did the saline controls [see Figure 1; drug, $F(1,34)$ $=11.04, p<.005]$. Neither the retention interval main effect nor the drug $\times$ retention interval interaction even approached significance [retention interval, $F(1,34)=$ $0.12, p>.10$; drug $\times$ retention interval interaction, $F(1,34)=1.40, p>.10]$.

As can be seen in Figure 2, the animals in the massed acquisition condition/short retention interval, as well as

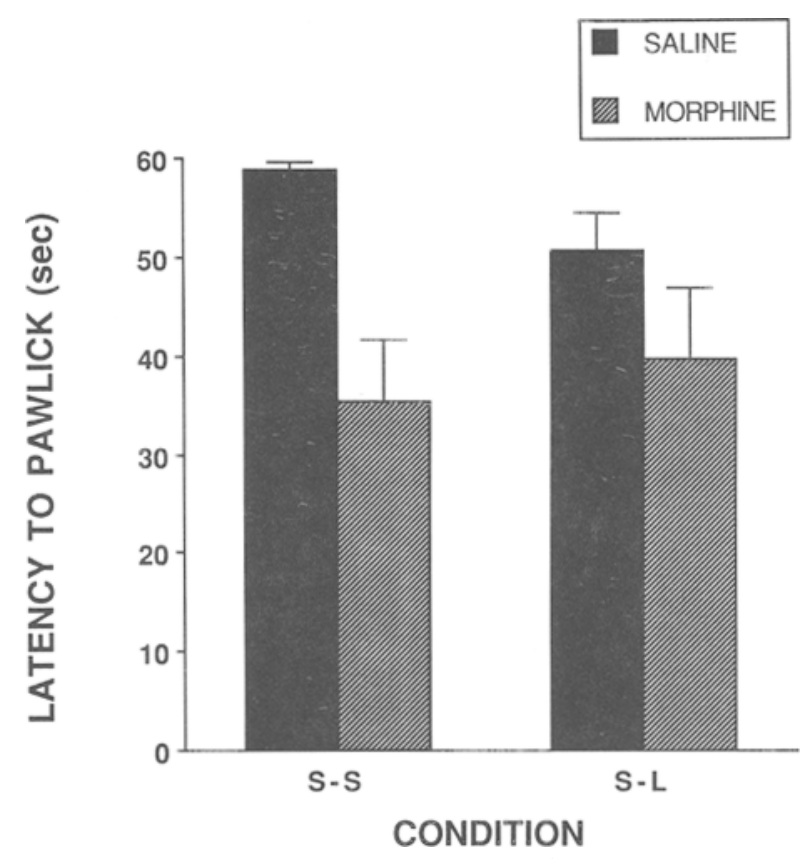

Figure 1. Mean ( $\pm S E M$ ) latency to hindpaw lick in a botplate test of nociception. S-S = spaced acquisition condition/short retention interval. $\mathbf{S}-\mathbf{L}=$ spaced acquisition condition/long retention interval. (The animals were tested $30 \mathrm{~min}$ after exposure to a probe dose of morphine [10 $\mathrm{mg} / \mathrm{kg}$, i.p.].) 


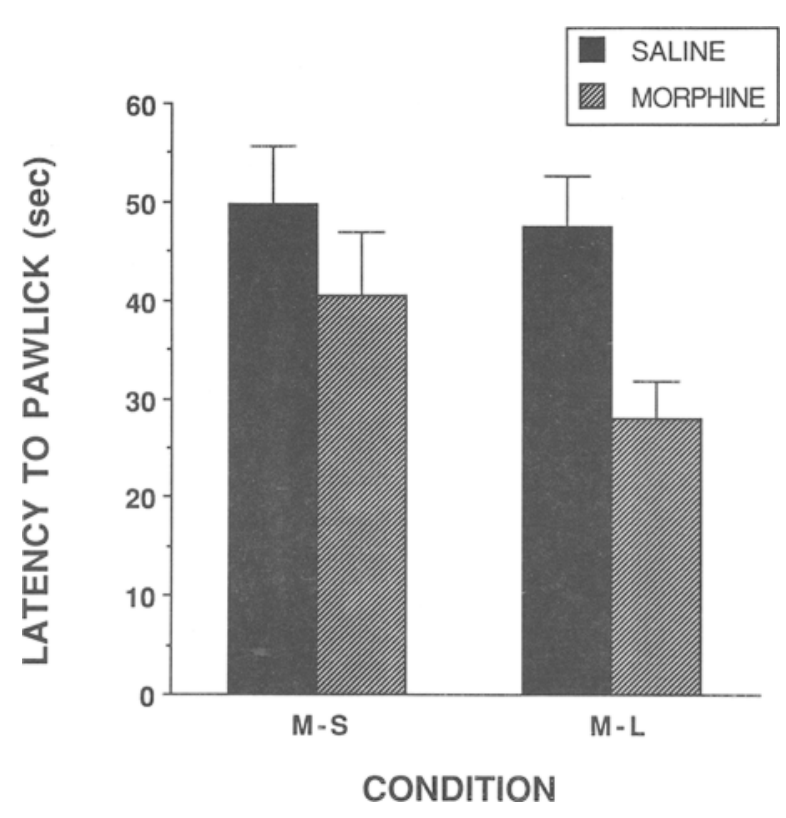

Figure 2. Mean $( \pm S E M)$ latency to hindpaw lick in a hotplate test of nociception. $\mathbf{M}-\mathrm{S}=$ massed acquisition condition/short retention interval. $\mathbf{M}-\mathbf{L}=$ massed acquisition condition/long retention interval. (The animals were tested $30 \mathrm{~min}$ after exposure to a probe dose of morphine [10 $\mathrm{mg} / \mathrm{kg}$, i.p.].)

the animals in the massed acquisition condition/long retention interval, also displayed shorter pawlick latencies than did their respective saline controls [drug, $F(1,33)=6.83$, $p<.02]$. In fact, the animals in the massed acquisition condition/long retention interval appear to have been even more tolerant, as compared with the saline controls, than the animals in the massed acquisition condition/short retention interval (Student-Newman-Keuls, $p<.05$ ). This finding is the opposite of what Baker and Tiffany's (1985) theory predicts. Neither the retention interval main effect, nor the drug $\times$ retention interval interaction approached significance [retention interval, $F(1,33)=1.88$, $p>.10$; drug $\times$ retention interval interaction, $F(1,33)$ $=0.88, p>.10$ ]. Importantly, these results indicate that tolerance resulting from massed or "short-term" acquisition parameters (Tiffany \& Maude-Griffin, 1988) is long-lasting.

It is important to consider, however, that for short-term tolerance to occur there must be a continued representation of morphine in STM. Noting Paletta and Wagner's (1986) data concerning the temporal characteristics of morphine's activity, it seems unlikely that Tiffany and Maude-Griffin's (1988) 24-h IDI met this criterion, despite their high acquisition dose $(30 \mathrm{mg} / \mathrm{kg})$. In fact, previous data indicate that signs of morphine abstinence appear as early as $12 \mathrm{~h}$ after morphine administration (Gellert, Eisenberg, \& Sparber, 1976). Consequently, it is possible that the parameters selected by Tiffany and Maude-Griffin (1988) were not sufficient for the acquisition of short-term tolerance. Therefore, a more appropriate test of their theory would be to employ a method of morphine administration that would result in a sustained presence of morphine, such as morphine-pellet implants or a chronic pump. The chronic pump would appear to be the most desirable, however, because morphine could be administered continuously and many of the "preinjection" or "preimplantation" rituals associated with repeated injections or pellet implantations, respectively, would be eliminated. Furthermore, the rate of infusion would be continuous, thus eliminating peaks and troughs in drug level and consequent cyclic withdrawal associated with these other methods of drug administration (Gellert \& Sparber, 1977; Schaefer \& Michael, 1986). Therefore, in the second experiment the method of continuous infusion was selected.

\section{EXPERIMENT 2}

\section{Method}

Subjects. The subjects in the second experiment were male Sprague-Dawley rats (Dominion Laboratories, Dublin, VA), initially weighing approximately $250-300 \mathrm{~g}$. ${ }^{3}$ The animals were housed individually, with food and tap water continuously available, on a 12:12-h light:dark cycle. The experiments were conducted during the light phase. All animals were preexposed to handling for several days prior to the start of the experiment. A total of 35 animals provided an $N$ of $7-11 /$ cell.

Procedure. The animals were implanted with 7-day-duration osmotic minipumps (Alzet Model 2ML1, Alza) containing either morphine sulphate $(60 \mathrm{mg} / \mathrm{kg} /$ day, s.c.) or water following the procedure and doses previously described (Lightman \& Young, 1987; Schaefer \& Michael, 1986). Water was employed as the vehicle in the second experiment because it produces less edema and irritation around the pump than isotonic saline does. Immediately preceding the pump implantation, the animals were briefly preexposed to the hotplate (Adams et al., 1969; Advokat, 1981; Bardo \& Hughes, 1979; Kayan et al., 1969; Sherman et al., 1982). The animals were tested either 4 or 7 days after the cessation of drug preexposure.

On the day of testing, all animals were administered a probe dose of morphine previously found in pilot studies to discriminate between morphine-tolerant and morphine-naive animals $(15 \mathrm{mg} / \mathrm{kg}$, i.p.), ${ }^{4}$ and they were then returned to their home cages. Thirty minutes later, they were removed from their cages and gently placed on the hotplate surface $\left(51.5^{\circ} \pm 0.5^{\circ} \mathrm{C}\right)$. As before, latency to lick a hindpaw, to the nearest second, was the dependent measure. Animals not licking a hindpaw before the 60 -sec cutoff were given the maximum score.

\section{Results and Discussion}

As can be seen in Figure 3, continuous infusion of morphine via the osmotic minipump resulted in a diminished responsivity to a probe dose of morphine relative to the responsivity of morphine-naive controls. Morphine preexposed animals, regardless of retention interval (short or long), displayed significantly shorter pawlick latencies than did the water-pretreated controls, indicating that tolerance had occurred [drug, $F(1,31)=67.01$, $p<.001]$. Neither the retention interval main effect nor the drug $\times$ retention interval interaction even approached significance [retention interval, $F(1,31)=0.353$, $p>.10$; drug $\times$ retention interval interaction, $F(1,31)$ $=2.22, p>.10]$. In other words, continuous exposure 


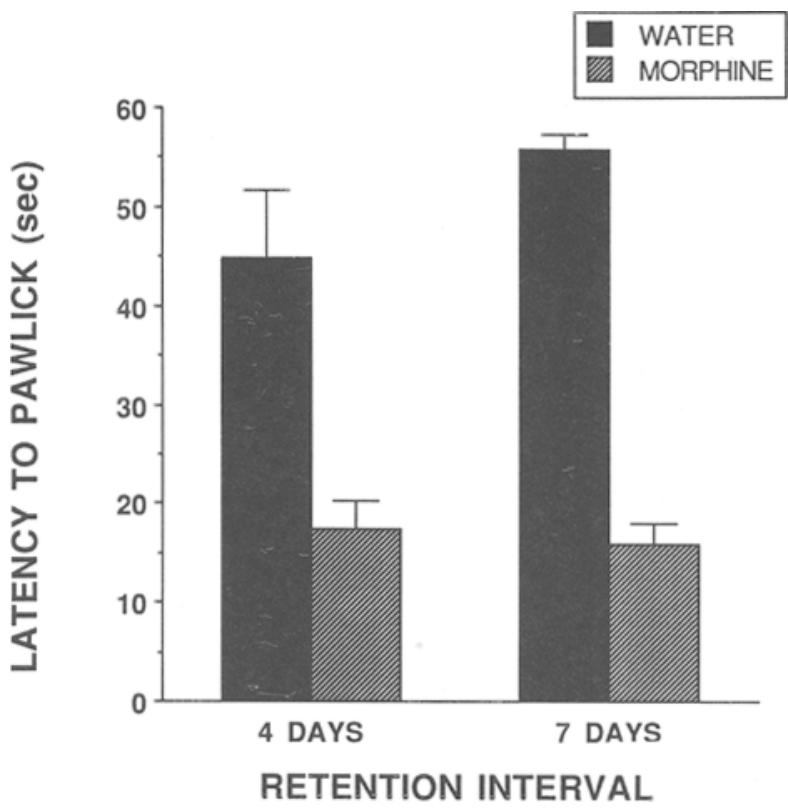

Figure 3. Mean ( \pm SEM) latency to hindpew lick in a hotplate test of nociception. Retention interval refers to the number of days after cessation of drug preexposure testing was conducted. (The animals were tested $30 \mathrm{~min}$ after exposure to a probe dose of morphine [15 mg/kg, i.p.].)

to morphine produced long-lasting tolerance. Since this infusion should maintain a more constant representation in STM than even the most closely spaced injection regimen, the data again fail to support the priming model of tolerance (Baker \& Tiffany, 1985; Paletta \& Wagner, 1986).

\section{GENERAL DISCUSSION}

Several researchers have indicated that tolerance to the antinociceptive effects of morphine follows the laws of Pavlovian conditioning. These theories can be divided into two categories: conditioned compensatory response models (Eikelboom \& Stewart, 1982; MacRae et al., 1987; Siegel, 1975) and priming models (Baker \& Tiffany, 1985; Paletta \& Wagner, 1986). The priming models predict two types of tolerance: long and short term, which are mediated by associative and nonassociative mechanisms, respectively (Baker \& Tiffany, 1985; Paletta \& Wagner, 1986). Siegel's conditioned compensatory response model (1975), on the other hand, suggests that all tolerance is associative and long-lasting.

In this study, we tested two hypotheses generated by the priming model: first, that short and long retention tolerance should develop at the expense of each other, and second, that only tolerance resulting from spaced acquisition parameters should be long-lasting (Baker \& Tiffany, 1985). The results indicate that all animals preexposed to morphine, regardless of acquisition condition, were tolerant to its antinociceptive effects. In fact, the animals in the massed acquisition condition/long retention interval were even more tolerant at the time of testing than were the animals in the massed acquisition condition/short retention interval. Furthermore, we conducted an additional test of the animals in Experiment 214 days after the cessation of morphine pretreatment. These retested animals continued to show diminished responsivity to morphine-induced antinociception indicative of tolerance $(p<.05)$. In summary, we view the continuous administration procedure as a particularly strong test of the priming models of tolerance. When this procedure is used, the data do not support these models.

Again, because associative manipulations were not intentionally introduced, long-term tolerance was operationally defined as tolerance that outlasted the presence of the drug stimulation. Furthermore, in the second experiment, no provisions for context were made; the pumps were implanted and testing was conducted in the same room. Therefore, it is difficult to determine whether the tolerance was associative, and if it was, what the actual CS may have been. By suggesting that some forms of tolerance are nonassociative or cue-independent, supporters of the priming model imply that they know exactly what the CS in conditioned tolerance is. However, as Wagner (1976) suggests, the cue that reliably predicts the US might actually be a "situational cue" rather than the cue nominally labeled as the CS. Wagner suggests that when explicit cues are not provided, the situational or contextual cues gain in importance. Therefore, in Experiment 2, in which context was not controlled, certain situational cues associated with the onset of morphine administration (e.g., the initial stimulation from the drug; see Walter \& Riccio, 1983) may have been more relevant stimuli for morphine's later antinociceptive effects than the somewhat arbitrarily assigned nominal CSs (e.g., odors, lighting) previously employed in conditioned tolerance experiments.

\section{REFERENCES}

Adams, W. J., Yeh, S. Y., Woods, L. A., Mrtchell, C. L. (1969). Drug-test interaction as a factor in the development of tolerance to the analgesic effect of morphine. Journal of Pharmacology \& Experimental Therapeutics, 2, 251-257.

ADvokat, C. (1981). Analgesic tolerance produced by morphine pellets is facilitated by analgesic testing. Pharmacology, Biochemistry \& Behavior, 14, 133-137.

BAKER, T. B., \& TIFFANY, S. T. (1985). Morphine tolerance as habituation. Psychological Review, 92, 78-108.

BARDo, M. T., Hughes, R. A. (1979). Exposure to a nonfunctional hot plate as a factor in the assessment of morphine-induced analgesia and analgesic tolerance in rats. Pharmacology, Biochemistry \& Behavior, 10, 481-485.

Budavari, S. (Ed.) (1989). Merck index (11th ed.). Rahway, NJ: Merck \& Co.

Cohen, M., KeAts, A. S., Krivoy, W., \& Ungar, G. (1965). Effect of actinomycin D on morphine tolerance. Society for Experimental Biology \& Medicine; Proceedings, 119, 381-384.

DAFTERS, R., \& BACH, L. (1985). Absence of environment-specificity in morphine tolerance acquired in non-distinctive environments: Habituation or stimulus overshadowing? Psychopharmacology, 87, 101-106. 
DAFTERS, R., \& ODBER, J. (1989). Effects of dose, interdose interval, and drug-signal parameters on morphine analgesic tolerance: Implications for current theories of tolerance. Behavioral Neurascience, 103, $1082-1090$.

DAFTERS, R. I., OdBer, J., \& Miller, J. (1988). Associative and nonassociative tolerance to morphine: Support for a dual-process habituation model. Life Sciences, 42, 1897-1906.

DAvIs, M. (1970). Effects of interstimulus interval links and variability on startle-response habituation in the rat. Journal of Comparative \& Physiological Psychology, 72, 177-192.

EIKELBOOM, R., \& STEWART, J. (1982). Conditioning of drug-induced physiological responses. Psychological Review, 89, 507-528.

GARCIA, J., \& KoELLING, R. A. (1966). Relation of cue to consequence in avoidance learning. Psychonomic Science, 4, 123-124.

Gellert, V. F., Eisenberg, R., \& Sparber, S. B. (1976). Operant behavioral disnuption, aggression and elevated plasma corticosterone twelve hours after morphine in rats on a twice per day injection schedule. Pharmacologist, 18, 176.

Gellert, V. F., SPARBer, S. B. (1977). A comparison of the effects of naloxone upon body weight loss and suppression of fixed-ratio operant behavior in morphine-dependent rats. Journal of Pharmacology \& Experimental Therapeutics, 201, 44-54.

Kayan, S., Woods, L. A., Mitchell, C. L. (1969). Experience as a factor in the development of tolerance to the analgesic effect of morphine. European Journal of Pharmacology, 6, 333-339.

KESNER, R. P., COOK, D. G. (1983). Role of habituation in classical conditioning in the development of morphine tolerance. Behavioral Neuroscience, 97, 4-12.

Lightman, S. L., Young, W. S. (1987). Changes in hypothalamic preproenkephalin A mRNA following stress and opiate withdrawal. Nature, 328, 643-645.

MacRae, J. R., Scoles, M. T., \& Siegel, S. (1987). The contribution of Pavlovian conditioning to drug tolerance and dependence. British Journal of Addiction, 82, 371-380.

McLaughlin, C. R., Lichtman, A. H., Fanselow, M. S., Cramer, C. P. (1989). Pro-leu-gly- $\mathrm{NH}_{2}$ serves as a conditioned stimulus in the acquisition of conditioned tolerance. Behavioral Neuroscience, 103, 447-451.

Pavlov, I. P. (1960). Conditioned reflexes (G. V. Anrep, Ed. and Trans.). New York: Dover. (Original work published 1927)

Paletta, M. S., \& WAgner, A. R. (1986). Development of contextspecific tolerance to morphine: Support for a dual-process interpretation. Behavioral Neuroscience, 100, 611-623.

SCHAEFER, G. J., \& MiChaEL, R. P. (1986). Changes in response rates and reinforcement thresholds for intracranial self-stimulation during morphine withdrawal. Pharmacology, Biochemistry \& Behavior, 25, 1263-1269.

Sherman, J. E., Proctor, C., \& Strub, H. (1982). Prior hot plate exposure enhances morphine analgesia in tolerant and drug-naive rats. Pharmacology, Biochemistry \& Behavior, 17, 229-232.

Siegel, S. (1975). Evidence from rats that morphine tolerance is a learned response. Journal of Comparative \& Physiological Psychology, 89, 498-506.
Smith, A. A., Karmin, M., \& Gavitt, J. (1966). Blocking effect of puromycin, ethanol, and chloroform on the development of tolerance to an opiate. Biochemical Pharmacology, 15, 1877-1879.

TIFFANY, S. T., \& BAKER, T. B. (1981). Morphine tolerance in rats: Congruence with a Pavlovian paradigm. Journal of Comparative \& Physiological Psychology, 95, 747-762.

Tiffany, S. T., \& Maude-Griffin, P. M. (1988). Tolerance to morphine in the rat: Associative and nonassociative effects. Behavioral Neuroscience, 102, 534-543.

WAGNer, A. R. (1976). Priming in STM: An information processing mechanism for self-generated or retrieval-generated depression in performance. In T. J. Tighe \& R. N. Leaton (Eds.), Habituation: Perspectives from child development, animal behavior and neurophysiology (pp. 95-128). Hillsdale, NJ: Erlbaum.

WAGNER, A. R. (1978). Expectancies and the priming of STM. In S. H. Hulse, H. Fowler, \& K. W. Honig (Eds.), Cognitive processes in animal behavior (pp. 177-209). Hillsdale, NJ: Erlbaum.

WAlter, T. A., Riccio, D. C. (1983). Overshadowing effects in the stimulus control of morphine analgesic tolerance. Behavioral Neuroscience, 97, 658-662.

WOOLFE, G., MAcDonald, A. D. (1944). The evaluation of the analgesic action of pethidine hydrochloride (Demerol). Journal of Pharmacology \& Experimental Therapeutics, 80, 300-307.

\section{NOTES}

1. Because we did not intentionally manipulate associative cues, and, hence, did not directly test Siegel's (1975) conditioned compensatory response model, long-term tolerance is operationally defined as the tolerance that remains after the physiological drug stimulation is no longer present.

2. In addition, all tolerance acquisition and testing were conducted in the presence of strong olfactory, visual, and auditory contextual cues (pine or Lysol odor, bright light and white noise, respectively). This was done to create a distinctive environment and facilitate the formation of associative tolerance. Data from Tiffany and Maude-Griffin (1988), on the other hand, indicate that the presence of strong contextual cues would have no detrimental effect on the formation of shortterm tolerance.

3. Due to the rather limited solubility of morphine sulfate $(1 \mathrm{~g}$ dissolves in $15.5 \mathrm{ml}$ of water at $25^{\circ} \mathrm{C}$ [Budavari, 1989]) and the pump volume of $2 \mathrm{ml}$, smaller animals $(<300 \mathrm{~g}$ ) were employed in Experiment 2 so that we could administer the required dose of $60.0 \mathrm{mg} / \mathrm{kg} /$ day for 7 days.

4. In pilot studies, the previous probe dose of $10 \mathrm{mg} / \mathrm{kg}$ failed to significantly increase the pawlick latencies of morphine-naive animals. Consequently, the probe dose of morphine was increased to $15 \mathrm{mg} / \mathrm{kg}$ in Experiment 2. Possible explanations for this difference may be that the animals employed in the two experiments were different strains from different suppliers tested on different hotplates in different laboratories.

(Manuscript received January 25, 1991; revision accepted for publication May 31, 1991.) 